\title{
Fast-Track Kardiyak Anestezide İntratekal Morfin Uygulaması
}

\section{Intrathecal Morphine Administration in Fast-Track Cardiac Anesthesia}

\author{
Gülsen KESKIN ${ }^{1}$, , Sumru ŞEKERCi ${ }^{(\mathbb{D})}$, Mehmet Murat SAYIN ${ }^{1}$ (D) , Berna TAŞ ÖNAL ${ }^{3} \mathbb{D}$, Haluk GÜMÜŞ ${ }^{1}$ \\ ${ }^{1}$ SBÜ, Dışkapı Yıldırım Beyazıt Eğitim ve Araştırma Hastanesi, Anesteziyoloji ve Reanimasyon Kliniği, Ankara, TÜRKiYE \\ ${ }^{2}$ Ankara Şehir Hastanesi, Anesteziyoloji ve Reanimasyon Kliniği, Ankara, TÜRKiYE \\ ${ }^{3}$ Seyhan Devlet Hastanesi, Anestezi Kliniği, Adana, TÜRKiYE
}

öz.

Amaç: Fast-track (Erken derlenme) kardiyak anestezi protokolünde $10 \mu \mathrm{g} / \mathrm{kg}$ dozunda intratekal morfin uygulamasının postoperatif analjezi ve erken derlenme üzerine etkisini araştırmayı planladık.

Materyal ve metod: Elektif koroner bypass greftleme (KABG) operasyonu planlanan ASA I-III grubundan 42 hasta, kapalı zarf usulü ile intratekal morfin (ITM) ve kontrol (K) grubu olarak iki gruba ayrıldı. iTM grubuna indüksiyondan önce $10 \mu \mathrm{g} / \mathrm{kg}$ dozundan morfin intratekal olarak uygulandı. Her iki gruba aynı anestezi indüksiyon ve idame yöntemi kullanıldı. Yoğun bakımda her iki gruba hasta kontrollü analjezi (HKA) ile tramadol başlandı. İntraoperatif hemodinamik parametreler, ekstübasyon süresi, sedasyon skoru, VAS skoru, postoperatif akciğer kapasitesi, VAS skoru, yoğun bakım ve hastanede kalış süresi kaydedildi.

Bulgular: Her iki grubun demografik verileri ve intraoperatif verileri arasında fark yoktu $(p>005)$.

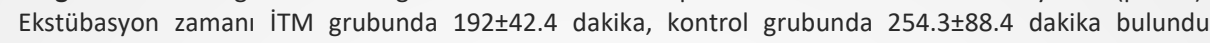
$(\mathrm{p}<0.05)$. Postoperatif ağrı skorları, tramadol tüketimi, akciğer volümleri ve yoğun bakımda kalış süresi ITM grubunda daha iyi bulundu $(p<0.05)$. Hastanede kalış süreleri benzerdi.

Sonuç: $10 \mu \mathrm{g} / \mathrm{kg}$ dozunda intratekal morfin uygulaması, kardiyak cerrahi sonrası çok iyi analjezi, akciğer volümlerinde daha erken derlenme ve daha kısa yoğun bakım kalış süresi sağladı.

Anahtar Kelimeler: Kardiyak anestezi, Fast-track, İntratekal morfin, Desfluran, Remifentanil

\section{Abstract}

Background: We aimed to investigate the effect of $10 \mu \mathrm{g} / \mathrm{kg}$ intrathecal morphine administration in the fast-track cardiac anesthesia protocol on postoperative analgesia and fast-tracking.

Materials and Methods: 42 patients from ASA I-III group undergoing elective coronary bypass grafting (CABG) were divided into two groups as intrathecal morphine (ITM) and control (K) groups by closed envelope method. Morphine at a dose of $10 \mu \mathrm{g} / \mathrm{kg}$ was intrathecally administered to the ITM group before induction. The same method of anesthesia induction and maintenance was used in both groups. Patient controlled analgesia (PCA) and tramadol were started in both groups in the intensive care unit. Intraoperative hemodynamic parameters, extubation time, sedation score, VAS score, capacity of lung, analgesia, time of intensive care and hospital stay were recorded.

Results: There was no difference between demographic data and intraoperative data of both groups ( $p>$ 005). The extubation time was $192 \pm 42.4$ minutes in the ITM group and $254.3 \pm 88.4$ minutes in the control group $(p<0.05)$. Postoperative pain scores, tramadol consumption, lung volumes and length of stay in intensive care were better in the ITM group $(p<0.05)$. Length of stay in the hospital was similar.

Conclusion: Intrathecal morphine administration at a dose of $10 \mu \mathrm{g} / \mathrm{kg}$ provided very good analgesia after cardiac surgery, earlier recovery in lung volumes and shorter intensive care stay.

Key Words: Cardiac anesthesia, Fast-track, Intrathecal morphine, Desflurane, Remifentanil
Sorumlu Yazar/Corresponding Author

\section{Dr. Gülsen KESKIN}

Üniversiteler mah. 1598 sok. Kümeevleri 17/22, 06800- Çankaya, Ankara, TÜRKiYE

E-mail:drgulsenkeskin@gmail.com

Geliş tarihi / Received: 29.12.2020

Kabul tarihi / Accepted: 11.06.2021

DOI: $10.35440 /$ hutfd. 849009

XXXVIII. Türk Anesteziyoloji ve Reanimasyon Kongresi, 1-5 Aralık 2004, Antalya'da sözlü bildiri olarak sunulmuştur.

Bu çalışma Dr Gülsen Keskin'in tıpta uzmanlık tezinden üretilmiştir 


\section{Giriş}

Fast-track protokolü erken ekstübasyon sağlayan ve yoğun bakımda kalış süresini kısaltan bir yöntemdir. İlk kez Krohn ve ark.ları 1990'da kardiyak operasyonlardan sonra hızlı derlenme adını verdikleri bir çalışma yayınlamışlardır (1). Bu protokol ile hastaların postoperatif 4-6 saat içinde ekstübe edilmeleri, yoğun bakımda 24 saat kalmaları ve taburculuk sürelerinin 6 günden kısa olması hedeflenir. Bu nedenle kısa etkili ve kolay titre edilebilen ajanların kullanılması daha uygundur. Remifentanil, kolay titre edilebilen ilk ultra kısa etkili opioidtir. Derin intraoperatif analjezi ve hemodinamik stabilite sağlamakla beraber erken ekstübasyon ve derlenmeye de imkan verir (2). İnhalasyon anesteziklerinden desfluran düşük kan:gaz çözünürlüğü ile etkisi hızlı başlar ve hızlı uyanma sağlar. Desfluran-remifentanil anestezisi hızlı derlenme sağladığı için uygun kombinasyon gibi görünmektedir. $(3,4)$. Bispektral index (Bis) monitorizasyonu, gereksiz ilaç tüketimini azaltarak hızlı derlenmeye imkan sağlar ve hemodinamik stabiliteye yardımcı olur (5). Ekstübasyonda uzamaya neden olmadan yeterli analjezi sağlanması da bu protokolün en zor bölümünü oluşturur. İntratekal uygulamalar emniyetli oluşu, kolay uygulanabilmesi düşük dozlarda yeterli analjezi sağlaması gibi avantajları nedeniyle tercih edilirler. Morfin etkinliği ve etki süresinin uzun olması nedeniyle intratekal uygulamalarda en çok kullanılan opioiddir (6). Morfin, intratekal olarak kullanıldığında ağrı yolaklarını spinal düzeyde etkiler. Posterior spinal kord üzerinde bulunan substansia gelatinosadaki opioid reseptörlerini aktive ederek presinaptik inhibisyon yapar ve bu düzeydeki anljezik etkide Mü $_{1}$ reseptörlerin yeri yoktur (7).

Bu çalışmada, Fast-track kardiyak anestezi protokolünde $10 \mu \mathrm{g} / \mathrm{kg}$ dozunda kullanılan intratekal morfin uygulamasının intraoperatif hemodinami, postoperatif ekstübasyon, sedasyon, analjezi, akciğer volümleri, yoğun bakım ve hastanede kalış sürelerine etkisini araştırmayı planladık.

\section{Materyal ve Metod}

Bu çalışma, Ankara Eğitim Hastanesi Baştabipliği Eğitim Planlama ve Koordinasyon Kurulu Başkanlığının onayı (07/04/2004 tarih ve /9 sayılı) alındıktan sonra, elektif koroner arter bypass greftleme (KABG) operasyonu planlanan ASA I-III grubundan 40 hasta dahil edilerek yapıldı. Hastalar kapalı zarf usulü ile randomize edilerek intratekal morfin (Grup ITM, $n=20$ ) ve kontrol (Grup K, $n=20$ ) grubu olarak ikiye ayrıldı.

Çalışmaya dahil edilen tüm hastalara operasyondan 1 saat önce $0.1 \mathrm{mg} / \mathrm{kg}^{\prime}$ a morfin, 0.03-0.05 mg/kg'a midazolam im olarak uygulandı. Operasyon odasına alınan hastaların, elektrokardiyografi (EKG) (D2-V5), pulse oksimetri ve invaziv arter basıncı, santral venöz basıncı, rektal ISISI, inhalasyon ajanının end-tidal konsantrasyonu ve anestezi derinliği monitörize edildi.

ITM grubundaki hastalara indüksiyon öncesi, 25 G spinal iğne ile lateral dekübit pozisyonda $L_{2-3}$ ya da $L_{3-4}$ aralığından $10 \mu \mathrm{g} / \mathrm{kg}$ (maksimum $500 \mu \mathrm{g}$ ) morfin hidroklorür verildi.
Kontrol grubuna etik olmadığı için subaraknoid enjeksiyon yapılmadı. ITM grubuna benzer şekilde $\mathrm{L}_{2-3-4}$ hizası steril spanç ile kapatıldı.

Her iki gruba, 3 dakika süreyle $\% 100$ oksijen ile preoksijenasyon uygulamasından sonra intravenöz yol ile $2 \mu \mathrm{g} / \mathrm{kg}$ fentanil, $0,3 \mathrm{mg} / \mathrm{kg}$ etomidat ve $0,6 \mathrm{mg} / \mathrm{kg}$ rokuronyum bromid verilerek anestezi indüksiyonu gerçekleştirildi. İndüksiyonu takiben her iki gruba da $5 \mu \mathrm{g} / \mathrm{kg} / \mathrm{min}$ infüzyon hızıyla remifentanil başlandı. Anestezi idamesi \%50 oksijen-medikal hava karışımı içerisinde \%3-6 konsantrasyonda desfluran ile sağlandı. 30 dakika arayla $0.15 \mathrm{mg} / \mathrm{kg}$ rokuronyum bromid uygulandı. Kardiyopulmoner baypassa (KPB) geçildiğinde desfluran kapatıldı ve $2 \mathrm{mg} / \mathrm{kg}$ propofol pompaya bolus uygulandı, eş zamanlı olarak $50 \mu \mathrm{g} / \mathrm{kg} / \mathrm{min}$ hızında infüzyona başlandı. İntraoperatif hemodinamik veriler, başlangıçta (bazal), entübasyon öncesi, entübasyon sonrası, insizyon öncesi, insizyon sonrası, sternotomi öncesi, sternotomi sonrası, kanülasyon öncesi, kanülasyon sonrası, KPB'ın 1., 5. dakikası, KPB'dan çıkış, sternum kapanması ve cerrahi bitiminde kaydedildi. Tüm hastalara membran oksijenatör nonpulsatil akım ile orta derecede hipotermik KPB uygulandı. Kan kardiyoplejisi kullanıldı.

Hastanın yoğun bakıma transferinden önce remifentanil infüzyonu sonlandırılarak $25 \mu \mathrm{g} / \mathrm{kg} / \mathrm{min}$ sedasyon dozunda propofol infüzyonuna başlandı. Yoğun bakım ekibine hastanın dahil olduğu çalışma grubu ile ilgili bilgi verilmedi.

Yoğun bakımda her iki gruba ağrı kontrolü için 12 saat ara ile 75 mg diklofenak sodyum im olarak uygulandı. HKA cihazı tramadolün bolus dozu $20 \mathrm{mg}$, aracın kilitli kalma süresi $20 \mathrm{dk}$ olacak şekilde hazırlandı. Hastalar ekstübasyonu takiben HKA cihazını kullanmaya başladılar ve bu uygulamaya 24 saat devam edildi. Hastaların ilk 6 saatlik ve 24 saatlik tramadol tüketimleri kaydedildi.

Oksijen yüzdesi $\left(\mathrm{FiO}_{2}\right)$ \%60'ın altında iken $\mathrm{P}_{\mathrm{a}} \mathrm{O}_{2} 90$ mmHg'ın üstünde seyrediyorsa, hasta normotermik ve hemodinamik olarak stabil ise kontrollü mekanik ventilasyondan senkronize intermitant mandatory ventilasyona (SIMV) geçildi ve propofol infüzyonu sonlandırıldı. Hasta uyanık, koopere, oryante, normal sinüs ritminde, göğüs tüpü drenajı $100 \mathrm{ml} / \mathrm{h}^{\prime}$ in altında, idrar çıkışı $0.5 \mathrm{ml} / \mathrm{kg} / \mathrm{h}^{\prime}$ in üzerinde iken akciğer fonksiyon testleri yeterli görüldüğünde sürekli pozitif hava yolu basıncı (CPAP)'a geçildi. Vital kapasite $12 \mathrm{ml} / \mathrm{kg}^{\prime} ı$ üzerinde, solunum sayısı 10-12 / dk, $\mathrm{pH}$ 7.3'ün üzerinde, $\mathrm{P}_{\mathrm{a}} \mathrm{O}_{2} 75$ mmHg'nın üzerinde, $\mathrm{PaCO}_{2} 50$ mmHg'nın altında ise akciğer fonksiyonları yeterli kabul edildi. CPAP uygulaması sırasında $\mathrm{PaCO}_{2}, 5 \mathrm{mmHg}$ dan daha fazla yükselmiyorsa hasta ekstübe edildi. Ekstübasyonu takip eden 0., 1., 2., 3., 4., 5., 6., 12. ve 24. saatlerde hastaların hastaların ağrı ve sedasyo skorları kaydedildi. Hastaların alt ekstremitelerinin nörolojik muayeneleri ağrı ve sedasyon skorlamaları ile eş zamanlı olarak yapıldı. Ağrı değerlendirilmesinde visual analog skala (VAS) ve verbal numerik skala (VNS) kullanıldı. Sedasyon skorlaması ise Ramsay skalası kullanılarak yapıldı.

Ekstübasyon zamanı 0. saat kabul edilerek 0., 1., 6., 12. ve 
24. saatlerde respirometre (Wright's pattern Haloscala ) ile tidal volüm (TV) ve zorlu vital kapasite (ZVK) ölçümleri yapılarak kaydedildi.

Postoperatif komplikasyonlar, müdahaleler ve ilaç gereksinimleri hasta taburcu edilene kadar kaydedildi. Nasal $\mathrm{O}_{2}$ desteği $4 \mathrm{~L} / \mathrm{min}$ altında iken $\mathrm{P}_{\mathrm{a}} \mathrm{O}_{2} 90 \mathrm{mmHg}$ ve üzerinde seyreden, idrar çıkışı $0.5 \mathrm{ml} / \mathrm{kg} / \mathrm{h}$ 'in üzerinde, göğüs tüpü drenajı $50 \mathrm{ml} / \mathrm{h}$ 'in altında olan ve inotropik ilaç desteğine gereksinim olmadan hemodinamisi stabil olan hastalar yoğun bakımdan servise alındılar.

\section{istatiksel Analiz}

İstatiksel değerlendirme için SPSS $9.01^{\circ}$ programı kullanıldı. Gruplar arası karşılaştırma Mann Whitney-U ve Ki-kare testleri kullanılarak yapıldı. Grup içi karşılaştırmalar başlangıç değerine göre Friedman-ANOVA, Wilcoxon testleriyle yapıldı. Zamana bağlı grup karşılaştırmalarında, Tekrarlayan Ölçümlerde ANOVA testi kullanıldı. $\mathrm{P}<0.05$ değeri istatiksel olarak anlamlı kabul edildi.

\section{Bulgular}

Gruplar arasında demografik özellikler, ASA fiziksel durum, vücut kitle indeksi (VKi), ejeksiyon fraksiyonu (EF) ve EuroSCORE açısından fark yoktu ( $p>0.05$ ) (Tablo 1$)$.

Tablo 1. Her iki grupta hastaların demografik verileri ve ASA, VKi, EF, EuroSCORE değerleri (Ort $\pm S D$ )

\begin{tabular}{lccc}
\hline & Grup iTM (n=20) & Grup K (n=20) & P değeri \\
\hline Yaş (yıl) & $58 \pm 8$ & $57 \pm 13$ & 1.00 \\
Cinsiyet (E/K) & $16 / 4$ & $14 / 6$ & 0.12 \\
Kilo (kg) & $72.1 \pm 10.5$ & $75.1 \pm 9.2$ & 0.38 \\
Boy (cm) & $163.9 \pm 8.3$ & $166.3 \pm 9.5$ & 0.31 \\
ASA (I/II/III) & $1 / 7 / 12$ & $2 / 18$ & 0.08 \\
VKi & $40.4 \pm 3.2$ & $40.7 \pm 2.5$ & 0.86 \\
Ejeksiyon Fraksiyonu(\%) & $54.6 \pm 6.8$ & $55.7 \pm 6.9$ & 0.62 \\
EuroSCORE & 3 & 3 & 0.66 \\
\hline EF; Ejeksiyon Fraksiyonu, VKi; vücut kitle indeksi, ASA; American Society \\
of Anesthesiologists Skoru
\end{tabular}

Kros-klemp ve kardiyopulmoner bypass (KPB) süresi, hipotermi derecesi, distal anastomoz sayısı, anastomoz başarıları ve anestezi süresi açısından gruplar arasında farklılık gözlenmedi (Tablo 2) ( $p>0.05$ ).

Yoğun bakıma geldikten göz açana kadar geçen süre gruplar arasında benzerlik gösterdi ( $p>0.05$ ) (Şekil 1).

Grupların ekstübasyon sonrası 0., 1., 2., 3., 4., 5., 6., 12. ve 24. saatlerdeki VAS değerleri şekil 2.'de verilmiştir. Gruplar arası istatiksel karşılaştırmada tüm zamanlarda ITM grubundaki VAS değerleri K grubuna göre anlamlı olarak düşük bulunmuştur $(p<0.05)$.

Her iki grubun ekstübasyon sonrası ilk 6 saatlik ve 24 saatlik tramadol tüketimleri Şekil 3.'de verilmiştir. 6. ve 24. saatlerdeki tramadol tüketimi iTM grubunda istatiksel olarak anlamlı düzeyde daha düşük bulunmuştur (iTM grubunda $16 \mathrm{mg}$, kontrol grubunda $195.5 \mathrm{mg}$ ) ( $\mathrm{p}<0.05$ ) (Şekil 3.).

Grupların ekstübasyon sonrası, 0., 1., 6. ve 24. saatlerdeki tidal volüm değerlerinin (TV) preoperatif değerleriyle karşılaştırılması Şekil 4.'de verilmiştir. TV değerleri, Grup
ITM'de ekstübasyon anında preoperatif değeriyle karşılaştırıldığında anlamlı olarak düşük, 1 . saat ve 6 . saatte preoperatif değeri ile farksız, 24. saatte ise preoperatif değerinden anlamlı olarak yüksek bulundu $(p<0.05)$. Grup K'da TV değerleri tüm zamanlarda preoperatif değerinden anlamlı olarak düşük bulundu $(p<0.05)$.

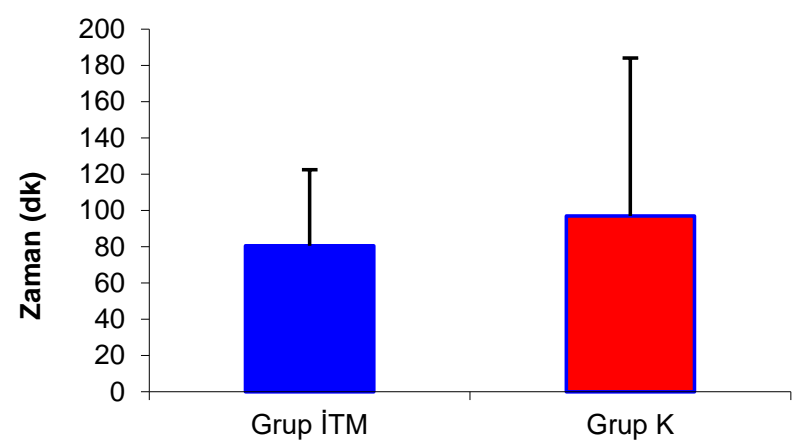

Şekil 1. Grupların yoğun bakıma geldikten sonra gözünü açana kadar geçen süre $(P>0.05)$

Tablo 2. Grupların intraoperatif verileri (Ort $\pm S D$ )

\begin{tabular}{lccc}
\hline & $\begin{array}{c}\text { Grup iTM } \\
(\mathbf{n = 2 0 )}\end{array}$ & $\begin{array}{c}\text { Grup K } \\
(\mathbf{n = 2 0 )}\end{array}$ & $\begin{array}{c}\boldsymbol{P} \\
\text { değeri }\end{array}$ \\
\hline Aortik kros-klemp süresi (dk) & $41.9 \pm 14.4$ & $46.3 \pm 30.2$ & 0.66 \\
KPB zamanı (dk) & $76.1 \pm 21.1$ & $87.9 \pm 38.9$ & 0.49 \\
Hipotermi derecesi $\left({ }^{\circ} \mathrm{C}\right)$ & $28.8 \pm 0.8$ & $28.9 \pm 1.2$ & 0.84 \\
Distal anastamoz $(1 / 2 / 3 / 4)$ & $(3 / 14 / 3 / 0)$ & $(7 / 8 / 4 / 1)$ & 0.22 \\
Eksik revaskülarizasyon & $8(\% 40)$ & $6(\% 30)$ & 0.60 \\
Tam revaskülarisyon & $12(\% 60)$ & $14(\% 70)$ & 0.60 \\
Kullanılan greft (LiMA/Safen) & $16 / 4$ & $12 / 8$ & 0.34 \\
Anestezi süresi (dk) & $223.7 \pm 33.5$ & $224.0 \pm 58.8$ & 0.99 \\
\hline KPB:Kardiyopulmoner Bypas & & &
\end{tabular}

KPB:Kardiyopulmoner Bypas

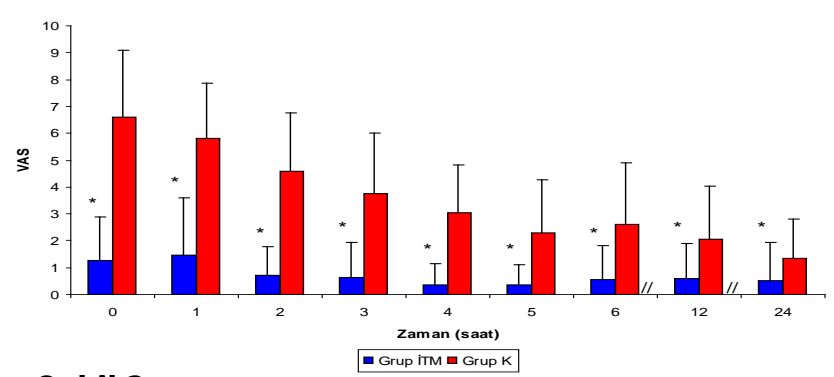

Şekil 2. Ekstübasyon sonrası ilk 24 saatteki VAS değerler $*(p<0.05)$

Tablo 3. Opioidlere bağlı yan etkiler ve postoperatif komplikasyonlar

\begin{tabular}{lcc}
\hline & Grup iTM (n=20) $\mathbf{n}(\%)$ & Grup K (n=20) $\mathbf{n}(\%)$ \\
\hline Kaşıntı & $1(\% 5)$ & $0(\% 0)$ \\
Bulantı & $11(\% 55)$ & $8(\% 40)$ \\
Kusma & $6(\% 30)$ & $5(\% 25)$ \\
İdrar retansiyonu & $0(\% 0)$ & $0(\% 0)$ \\
Postspinal başağrısı & $0(\% 0)$ & $0(\% 0)$ \\
Ventrikül taşikardisi & $0(\% 0)$ & $0(\% 0)$ \\
Atrial fibrilasyon & $0(\% 0)$ & $1(\% 5)$ \\
MI & $1(\% 5)$ & $0(\% 0)$ \\
Stroke & $0(\% 0)$ & $0(\% 0)$ \\
Re-entübasyon & $0(\% 0)$ & $0(\% 0)$ \\
Düşük debi sendromu & $0(\% 0)$ & $3(\% 15)$ \\
\hline
\end{tabular}


Opioidlere bağlı görülebilecek yan etkiler ve postoperatif oluşabilecek komplikasyonların grup içi dağılımları Tablo 3'de verilmiştir ( $p>0.05)$.

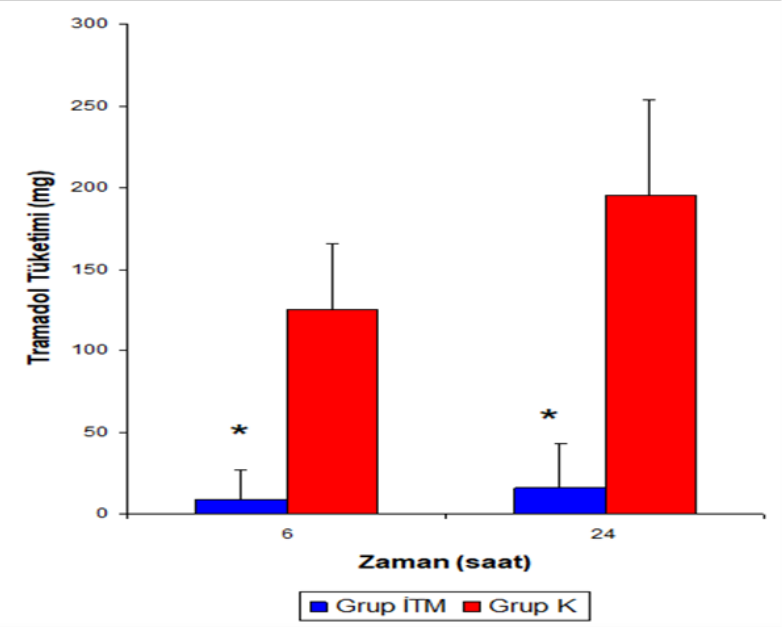

Şekil 3. Ekstübasyon sonrası 6. ve 24. Saatlerdeki tramadol PCA tüketimi $*(p<0.05)$

Yoğun bakımda izlenen parametreler, yoğun bakım ve hastanede kalış süreleri iki grup için Tablo 4'de verilmiştir. ITM grubunda ekstübasyon zamanı (192.3 \pm 42.4 dakika) kontrol grubuna kıyasla (254.3 \pm 88.4 dakika) anlamlı olarak daha kısa bulundu ( $p<0.05)$. Benzer şekilde yoğun bakımda kalış süresi de ITM grubunda daha kısaydı ( $p<0.05)$.

Tablo 4. Yoğun bakımda izlenen parametreler, yoğun bakım ve hastanede kalış süreleri (Ort \pm SD)

\begin{tabular}{|c|c|c|c|}
\hline & $\begin{array}{c}\text { Grup ITM } \\
(n=20)\end{array}$ & $\begin{array}{l}\text { Grup K } \\
(n=20)\end{array}$ & $\begin{array}{c}P \\
\text { değeri }\end{array}$ \\
\hline $\begin{array}{l}\text { Propofol inf sonlandırma za- } \\
\text { manı (dk) }\end{array}$ & $104.6 \pm 54.4$ & $138.5 \pm 87$ & 0.28 \\
\hline İlk göz açma zamanı (dk) & $80.5 \pm 41.9$ & $97.0 \pm 93.3$ & 0.62 \\
\hline Ekstübasyon zamanı (dk) & $192.3 \pm 42.4^{*}$ & $254.3 \pm 88.4$ & 0.01 \\
\hline Yoğun bakımda kalış süresi (sa) & $28.4 \pm 6.9^{*}$ & $39.0 \pm 10.2$ & 0.03 \\
\hline $\begin{array}{l}\text { Hastaneden taburculuk zamanı } \\
\text { (gün) }\end{array}$ & $6.2 \pm 0.9$ & $6.8 \pm 0.9$ & 0.10 \\
\hline
\end{tabular}

${ }^{*} p<0.05$ kontrol grubu ile kıyaslandığında

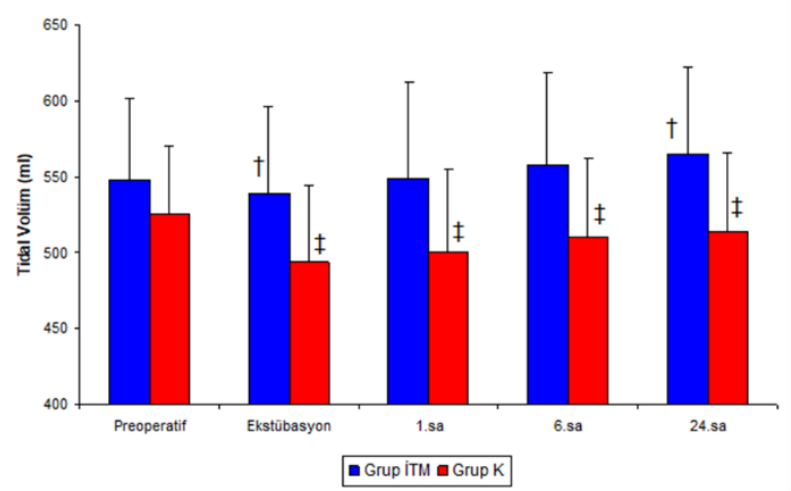

Şekil 4. Grupların preoperatif, ekstübasyon sonrası, ekstübasyon sonrası 1., 6. ve 24. saatlerdeki TV değerleri

+ Grup iTM'de TV değerleri preoperatif değeri ile karşılaştırıldığında $(p<0.05)$

‡ Grup K'da TV değerleri preoperatif değeri ile karşılaştıııldı̆̆ında ( $p<0.05$ )

\section{Tartışma}

Fast-track protokolü erken ekstübasyon ve mobilizasyon sağlayan, postoperatif kardiyopulmoner morbiditeyi azaltan, hasta konforunu arttıran bir metodtur (8). Bu metod yoğun bakım ve hastanede kalış sürelerini kısaltarak, hastane maliyetlerini düşürür, hasta sirkülasyonunu hızlandırır (9). Kardiyak cerrahi uygulanan hastalarda erken ekstübasyonun yararları bilinmekle birlikte erken ekstübasyon planlandığında, yüksek riskli hastalarda yeterli postoperatif ağrı kontrolü daha da önemlidir (10).

Intratekal morfinin kardiyak cerrahide uygulanması yeni bir yöntem değildir. Ancak intratekal morfin dozu ile ilgili henüz fikir birliği yoktur (11). Çalışmamızda, $10 \mu \mathrm{g} / \mathrm{kg}$ iTM'nin ekstübasyonu geciktirmeden güçlü bir analjezi sağladığını gördük.

Chaney ve ark. (12) $10 \mu \mathrm{g} / \mathrm{kg}$ iTM kullanarak yaptıkları çaIışmalarında ise kontrol grubuna göre daha az iv morfin tüketimi olmuş ancak istatiksel olarak anlamlı bulunmamıştır. Ortalama ekstübasyon zamanları çalışmamızdaki sürelerden daha uzun bulunmuştur. Araştırmacılar iTM'i, 20 mg/kg iv fentanil ile birlikte kullanmışlar ve ekstübasyon zamanlarını anlamlı artmış olarak bulmuşlardır. Zarate ve ark. (13) $8 \mu \mathrm{g} / \mathrm{kg}$ ITM ile yaptıkları çalışmalarında VAS skorlarında ve postoperatif morfin tüketiminde istatiksel olarak anlamlı azalma tesbit etmişler ekstübasyon sürelerini benzer bulmuşlardır. Vanstrum ve ark. (14) 0.5 mg ITM ile iv morfin kullanımında istatiksel anlamlı azalma görmüşler, ağrı skorlarında, ekstübasyon zamanlarında, yoğun bakım ve hastane kalış sürelerinde fark bulmamışlardır.

ITM, çok iyi postoperatif analjezi sağlamasına rağmen fasttrack protokolünün bir parçası olarak kullanıldığında solunum depresyonu ve ekstübasyonun gecikmesi gibi endişeleri beraberinde taşırRemifentanil gibi kısa etkili opioidlerin rezidüel solunum depresyonu etkisi çok azdır. Bu nedenle ITM kullanılan kardiyak cerrahi anestezide analjezik olarak remifentanil kullanıldığında fast-track protokolünü kolaylaştırabilir (15). Ahonen ve ark. (16) minimal invaziv KAB cerrahisinde iv propofol ile birlikte remifentanil 0.25 $0.5 \mu \mathrm{g} / \mathrm{kg} / \mathrm{min}$ infüzyonu veya alfentanil $0.5-1 \mu \mathrm{g} / \mathrm{kg} / \mathrm{min}$ infüzyonunu karşılaştırmışlar. Remifentanil grubunda uyanma ve ekstübasyon süreleri alfentanil grubuna göre istatiksel olarak anlamlı kısa bulunmuştur. Uyandıktan sonraki ilk 3 saatte morfin tüketimi remifentanil grubunda daha fazla bulunmuştur. Biz çalışmamızda $10 \mu \mathrm{g} / \mathrm{kg}$ iTM ile remifentanili $0.5 \mu \mathrm{g} / \mathrm{kg} / \mathrm{min}$ iv infüzyon hızı ile kullandık. Her iki grupta $0.5 \mu \mathrm{g} / \mathrm{kg} / \mathrm{min}$ iv infüzyon hızıyla uyguladığımız remifentanilin çok iyi intraoperatif hemodinamik stabilizasyon sağladığını gördük

Kardiyak cerrahi hastalarında yeterli postoperatif analjezi mortalite ve morbiditeyi azaltır (17). Birçok araştırmacı, rejyonal yöntemlerin kullanımıyla sağlanan yeterli analjezinin kardiyak cerrahiden sonra akciğer fonksiyonlarındaki bozulmaları iyileştirilebildiğini göstermişlerdir. Çalışmamızda pik ekspiratuar akım hızı, zorlu vital kapasite ölçümleri Grup ITM ve Grup K'da başlangıç değerleri ile karşılaştırıldığında istatiksel olarak anlamlı düşük bulundu. Ölçülen 
değerler ITM grubunda kontrol grubuna göre tüm zamanlarda başlangıç değerine istatiksel olarak daha yakın bulundu. Tidal volüm değerlerinin karşılaştırılmasında ise ITM grubunda 1. ve 6 . saat ölçümleri preoperatif değerinden farklı değildi, 24. saatte ölçülen değer ise preoperatif değerinden anlamlı olarak yüksekti. Bu sonuçlar daha önce yayınlanmış çalışmalarla uyumlu idi (18). Hiçbir hastada postoperatif atelektazi ve akciğer enfeksiyonu görmedik. İntrapulmoner şant oluşumunda düzelme sağlayabildiğimiz için hipoksi ile karşılaşmadık. Bunun nedeninin sağladığımız yeterli analjezi, buna bağı öksürük refleksinin ve inspirasyon derinliğinin yeterli olmasından dolayı olduğunu düşünüyoruz.

IT morfinin klasik dört yan etkisi vardır; kaşıntı, bulantıkusma, idrar retansiyonu ve solunum depresyonudur (19). Çalışmamızda ITM grubunda bir hastada tüm vücutta gelişen kaşıntı şikayeti oldu. Bu hastada klasik antihistaminik uygulamasına yanıt alındı. Bulantı-kusma her iki grupta gözlendi. İki grup arasında istatiksel olarak anlamlı fark yoktu. Hiçbir hastada idrar sondası çekildikten sonra idrar retansiyonu görülmedi.

ITM grubunda yoğun bakımda kalma süresi $28.4 \pm 6.9$ saat, kontrol grubunda $39 \pm 0.2$ saat idi. İki grup arasındaki süreler karşılaştırıldığında ITM grubunda yoğun bakımda kalma süresi anlamlı olarak kısa bulundu. Hastane taburculuk süreleri iTM grubunda 6.2 \pm 0.9 gün, kontrol grubunda 6.8 \pm 0.9 gün olarak hesaplandı. Gruplar arası karşılaştırmada istatiksel olarak anlamlı fark bulunmadı.

Sonuç olarak $10 \mu \mathrm{g} / \mathrm{kg}$ dozunda intratekal morfin kardiyak cerrahiye giden hastalarda yeterli ve güvenli postoperatif analjezi sağlamıştır.

Etik onam/çalışma izni: Bu çalışma, Ankara Eğitim Hastanesi Baştabipliği Eğitim Planlama ve Koordinasyon Kurulu Başkanlığının (07/04/2004 tarih ve 9 sayılı) kararı ile onaylanmıştır.

\section{Yazar Katkıları:}

Konsept: G.K., S.Ş., M.M.S.,

Literatür Tarama: G.K., B.T.Ö.,

Tasarım: G.K., S.Ş., M.M.S.,

Veri toplama: G.K., S.Ş., M.M.S., B.T.Ö.

Analiz ve yorum: G.K., S.Ş., M.M.S., H.G.

Makale yazımı: G.K., S.Ş., M.M.S.,

Eleştirel incelenmesi: G.K., S.S.., M.M.S., H.G.

Çıkar Çatışması: Herhangi bir çıkar çatışmamız bulunmamaktadır. Finansal Destek: Araştırma kapsamında herhangi bir kurum ya da kuruluştan finansal destek sağlanmamıştır.

\section{Kaynaklar}

1. Alhashemi JA, Sharpe MD, Harris CL, Sherman V, Boyd D. Effects of subarachnoid morphine administration on extubation time after coronary artery bypass graft surgery. J Cardiothorac Vasc Anesth 2000; 14:639-44.

2. Engoren $\mathrm{M}$, Luther $\mathrm{G}$, Fenn-Buderer N. A comparison of fentanil, sufentanil and remifentanil for fast-track cardiac anesthesia. Anesth Analg 2001; 93:859-64.

3. Zaugg $M$, Lucchinetti E, Garcia C, Pasch T, Spahn DR,
Schaub MC. Anaesthetics and cardiac preconditioning. Part II. Clinical implications. Br J Anaesth 2003; 91: 56676.

4. Aşkın T, Karadeniz Ü, Ünver S, Boran E, Erdemli Ö. An efficacy comparison of fentanyl and remifentanil during offpump coronary artery bypass graft surgery. Türk Göğüs Kalp Damar Cerrahisi Dergisi 2013; 21:683-90.

5. Bauer $M$, Wilhelm $W$, Kraemer $T$, Kreuer $S$, Brandt $A$, Adams HA, et al. Impact of bispectral index monitoring on stress response and propofol consumption in patients undergoing coronary artery bypass surgery. Anesthesiology 2004; 101:1096-104.

6. Chaney MA, Smith KR, Barclay JC, Slogoff S. Large-dose intrathecal morphine for coronary artery bypass grafting. Anesth Analg 1996; 83:215- 22.

7. Hindle A. Intrathecal opioids in the management of acute post operative pain. Cont Educ Anaesth Crit Care Pain 2008; 8(3): 81-85.

8. Silbert BS, Myles PS. Is fast-track cardiac anesthesia now the global standard of care? Anesth Analg 2009; 108:68991.

9. Wong WT, Lai VK, Chee YE, Lee A. Fast-track cardiac care for adult cardiac surgical patients. Cochrane Database Syst Rev. 2016 Sep 12;9(9):CD003587.

10. McCarthy C, Fletcher N. Early Extubation in Enhanced Recovery from Cardiac Surgery. Crit Care Clin 2020;36(4):663-74.

11. Jacobsohn E, Lee TW, Amadeo RJ, Syslak PH, Debrouwere $R G$, Bell $D$, et al. Low-dose intrathecal morphine does not delay early extubation after cardiac surgery. Can J Anaesth 2005;52(8):848-57.

12. Chaney MA, Furry PA, Fluder EM, Slogoff S. Intrathecal morphine for coronary artery bypass grafting and early extubation. Anesth Analg 1997; 84:241-8.

13. Zarate $E$, Latham $P$, White PF. Fast-track cardiac anesthesia: Use of remifentanil combined with intrathecal morphine as an alternative to sufentanil during desflurane anesthesia. Anesth Analg 2000; 91:283-7.

14. Vanstrum GS, Bjornson KM, Ilko R. Postoperative effects of intrathecal morfine in coronary artery bypass surgery. Anesth Analg 1988; 67:261-7.

15. de Hoogd S, Valkenburg AJ, van Dongen EPA, Daeter EJ, van Rosmalen J, Dahan A, et al. Short- and long-term impact of remifentanil on thermal detection and pain thresholds after cardiac surgery: A randomised controlled trial. Eur J Anaesthesiol 2019;36(1):32-39.

16. Ahonen J, Olkkola KT, Verkkala K. A comparison of remifentanil alfentanil for use with propofol in patientts undergoing minimally invasive coronary artey bypass surgery. Anesth Analg 2000; 90:1269-74.

17. Nachiyunde B, Lam L. The efficacy of different modes of analgesia in postoperative pain management and early mobilization in postoperative cardiac surgical patients: A systematic review. Ann Card Anaesth 2018;21(4):363-70.

18. Bowler I, Djaiani G, Abel R, Pugh S. A combination of intrathecal morphine and remifentanil anesthesia for fasttrack cardiac anesthesia and surgery. J Cardiothorac Vasc Anesth 2002; 16:709-14.

19. Ruan X. Drug-related side effects of long-term intrathecal morphine therapy. Pain Physician 2007;10(2):357-66. 